sala preta é uma publicação do Programa de Pós-Graduação em Artes Cênicas da Escola de Comunicações e Artes da USP. As opiniōes expressas nos artigos assinados são de inteira responsabilidade dos autores. Os artigos e documentos deste número foram publicados com a autorização de seus autores ou representantes.

Conselho Editorial

Antônia Pereira (UFBA)

Beatriz Cabral (UDESC)

Beth Rabetti (UNIRIO)

Christine Greiner (PUC-SP)

Flora Sussekind (UNIRIO)

Jacó Guinburg (USP)

Mariângela Alves de Lima

Sábato Magaldi (USP)

Coordenação Editorial

Luiz Fernando Ramos

Sílvia Fernandes

Projeto Gráfico

Yvone Saruê

Capa

Tânia Marcondes

Revisão e Editoracão

Discurso Editorial

Universidade de São Paulo

Reitora

Suely Vilela

Vice-reito

Hélio Nogueira da Cruz

Escola de Comunicação e Artes

Direto

Luís Milanesi

Vice-Diretor

Mauro Wilton de Souza

Presidente da Comissão de Pós-Graduação da ECA-USP

Maria Immacolata Vassalo Lopes

Coordenador do Programa de Pós-Graduação da ECA-USP

Luiz Fernando Ramos

Departamento de Artes Cênicas

Chefe

Felisberto Sabino da Costa

Vice-Chefe

Fausto Viana 
s revistas acadêmicas são ambientes propícios a acolher e germinar processos de investigação em curso. Quando essas publicaçōes abrangem o campo artístico, como é o caso da Sala Preta, combinam-se nesse quadro de pesquisas, experimentações que transcorrem paralelas aos projetos estritamente acadêmicos e que transbordam para além dos muros da Universidade. Mais do que ciência aplicada, tornada socialmente útil ou transformada em bem de consumo, a produção contemporânea na área de artes cênicas dilata a convergência entre teoria e prática e, dialeticamente, irriga tanto as resultantes artísticas quanto seus sucedâneos ou antecedentes conceituais.

Essa característica abunda no nono número da revista, dessa vez buscando ampliar o diálogo com os criadores e teóricos do velho continente europeu, bem como com a América do Norte.

A retranca de abertura, dedicada ao teatro português contemporâneo, exemplifica essa mirada além mar. O primeiro artigo traz o olhar brasileiro de Maria Helena Werneck para um dos principais coletivos portugueses de criação teatral, $\mathrm{O}$ Bando, e é seguido de um texto de seu líder, João Brites, narrando o percurso do grupo e suas experiências mais recentes com acontecimentos para-teatrais. Alexandre Calado informa sobre os currículos e práticas formativas em Portugal exemplificando com uma oficina realizada com Brites, e Rui Pina Coelho, um dos principais críticos em exercício na imprensa portuguesa e estudioso da dramaturgia contemporânea, apresenta o fascinante caso do romancista Gonçalo Tavares, e de como dois de seus chamados "livros pretos" foram encenados.

Marvin Carlson, o grande teórico norte-americano, analisa uma peça de um dos mais prolíficos dramaturgos lusos, Armando Nascimento Rosa, que também é objeto do escrutínio de Ana Maria de Bulhões-Carvalho, e colabora, ele próprio, com artigo em que formula as bases de seu projeto de dramaturgia

Ampliando o sobrevôo sobre a cena portuguesa, Paulo Eduardo Carvalho traça um panorama da atividade teatral na cidade do Porto, com destaque para a programação do Teatro Nacional de São João. José Simões de Almeida Júnior especula sobre os espaços cativos ao teatro na vida urbana e Ana Raquel Fernandes desdobra o tema numa busca da representação do espaço na atual dramaturgia luso-brasileira.

Concluindo esse amplo recenseamento do teatro português, Miriam Tavares especula sobre as relações entre teatro e cinema a partir de filme de João Mario Grilo, e Maria João Brilhante, a principal teórica nos estudos teatrais portugueses, observa neles os laços entre criação e reflexão crítica.

A segunda retranca, organizada pela encenadora Beth Lopes, foca na memória como elemento crucial na criação teatral. Lopes apresenta sua pesquisa recente que utiliza a análise do discurso como ferramenta no aproveitamento das reminiscências na elaboração de ações performativas. $\mathrm{O}$ ator e encenador francês, François Kahn, propõe a idéia de "improvisação estruturada" como forma do ator aproveitar sua memória involuntária, e a atriz e pesquisadora Tatiana Motta Lima especula, em profundidade, sobre a noção de memória como experiência em Grotowski. Yedda Carvalho Chaves resgata o sentido de memória associado ao corpo do ator, na elaboração de Meyerhold, e Zebba Dal Farra aproxima as idéias de memória coletiva e de rapsódia, focando no caso dos sambistas brasileiros. Finalmente, Patrícia Leonardelli sintetiza a pesquisa em que fez um histórico do conceito de memória para justificar, com base na análise de Bergson, a sua vocação de instrumento criativo.

O Dossiê de espetáculos destaca "Memória da Cana", uma das principais encenações do teatro brasileiro em 2009. O ator, dramaturgo, encenador e pesquisador Newton Moreno narra minuciosamente todas as etapas e dificuldades no longo processo de montagem. 
O ator Carlos Ataíde e a atriz Luciana Lira descrevem as experiências de construir suas interpretações fundindo os personagens de "Álbum de Família" de Nelson Rodrigues com suas memórias pessoais da infância no ambiente doméstico nordestino. Mariana Soutto Mayor, assistente de Moreno, detalha a tentativa de apreensão de uma memória coletiva no transcorrer dos ensaios, e Fátima Quintas, como especialista na sociologia de Gilberto Freyre, oferece uma rica descrição da família patriarcal brasileira. Cassiano Quilici contribui com uma leitura crítica e poética da empreitada da Cia Os Fofos Encenam.

A retranca Formação apresenta uma entrevista exclusiva com Josette Féral para a Sala Preta, realizada por Marcos Bulhões Martins e Verônica Veloso. O foco central desse diálogo são as relações entre a pedagogia do teatro e a noção de Féral de uma cena performativa. Maria Lúcia de Souza Barros Pupo examina as políticas culturais da cidade de Paris, partindo das atividades dos teatros subsidiados que transcendem apresentação de espetáculos e implicam em ações de formação e difusão.

Na sessão Drama e Pós-Drama reúnem-se trabalhos que abordam de ângulos diferenciados as questôes relativas à escritura dramática e seus sucedâneos. Rubens Rewald aborda a produção contemporânea de dramas e roteiros, delimitando traços comuns no teatro e no cinema em que as funçôes tradicionais de dramaturgo e roteirista se deslocam para uma participação mais ativa na ação de engendrar os espetáculos e os filmes. Stephan Baumgartel discute as potencialidades políticas do chamado teatro pós-dramático, à luz de Walter Benjamin e das relações entre as formas teatrais assim denominadas e a estética de Brecht. André Lage explicita as polêmicas advindas da publicação na França dos cadernos de Antonin Artaud. Escritos entre 1945 e 1946, no seu último ano de internação em Rodez, esse registros caligráficos podem ser lidos, ainda, como literatura, ou como desenhos e formas gráficas.

A retranca Teoria abriga alguns dos principais pensadores do teatro hoje. Beatrice Picon-Vallin debate as formas de inserção da tecnologia na cena do século 20, a partir de um recorte histórico e da percepção das especificidades na utilização do meio áudio visual por diversos encenadores. Richard Schechner comparece com um texto clássico produzido nos anos 1970 e que é traduzido pela primeira vez para o português. Ali são descritos os procedimentos criativos do Performance Group e estabelecidas as bases teóricas a partir das quais Schechner desenvolveu sua reflexão posterior. Jacó Guinsburg traduz o discurso de Eugênio Barba ao receber o título de Doutor Honoris Causa da Academia de Teatro e Música da Estônia e Oscar Cornago defende uma "teátrica pagã" com base nas idéias do filósofo Francês Jean-François Lyotard.

Teatro e Música contempla trabalhos de pesquisadores que operam na interseção entre as duas artes. Walter Garcia compartilha questôes musicais que colaboraram nos processos criativos da Cia do Latão. Maurílio Andrade Rocha associa a música popular e as questôes sociais com base numa montagem de "Mãe Coragem”. Ernani Maletta, com base em estratégia utilizada junto ao grupo Galpão, desenvolve o conceito de "atuação polifônica", em que a criação musical torna-se um elemento efetivo de formação do ator, e Fábio Cintra especula sobre a educação musical nas escolas de teatro em circunstâncias instáveis.

Resenhas de Maria Sílvia Betti, sobre o último livro de Hans-Thies Lehmann publicado no Brasil, e de Elisabeth Azevedo, sobre o resgate de Tãnia Brandão da companhia de Maria Della Costa e Sandro Polônio, complementam a revista. 


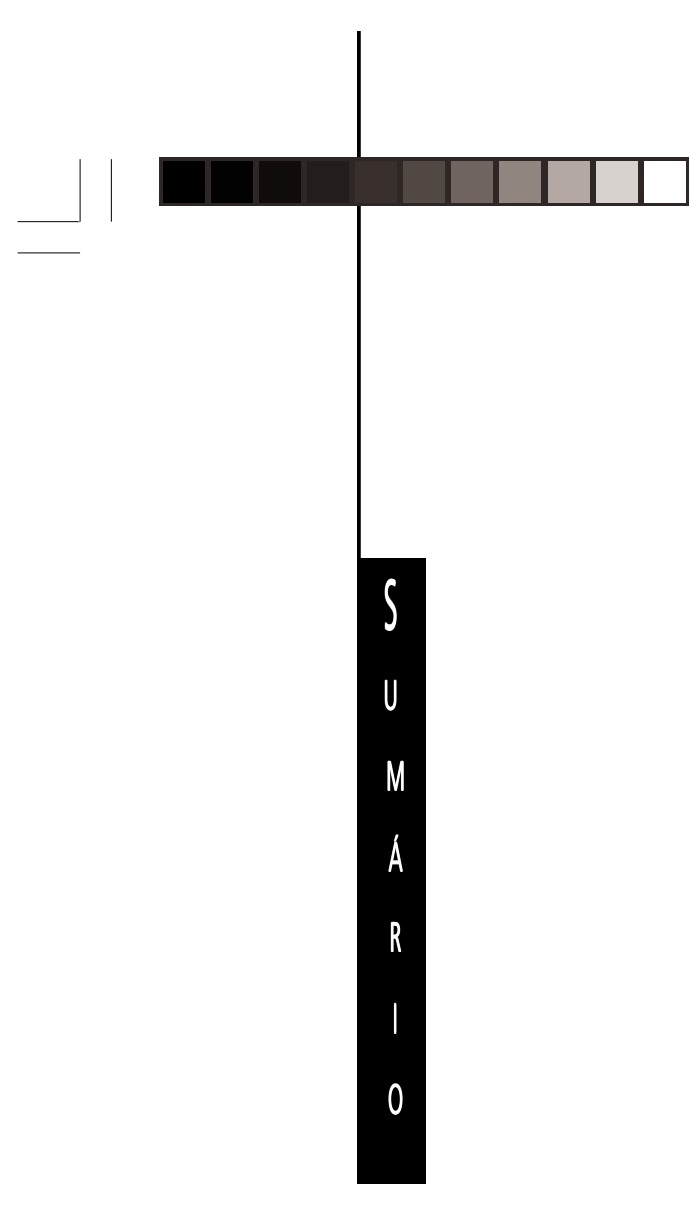

1. TEATRO PORTUGUÊS CONTEMPORÂNEO

$O$ Bando: um teatro de formas no ar Maria Helena Werneck, 9

O que fazer para conhecer melhor quem escreve na água?

João Brites, 21

O estranho caso do romancista e dos livros pretos que ele escreveu Rui Pina Coelho, 27

Sobre formar atores em Portugal Alexandre Calado, 37

Serpentes Copulantes Marvin Carlson, 49

O verbo da memória. Reflexóes sobre o teatro de Armando Nascimento Rosa Ana Maria de Bulhōes-Carvalho, 59

Notas para um teatro mitocrítico Armando Nascimento Rosa, 73

\section{Cartografia hesitante}

de uma experiência multiforme Paulo Eduardo Carvalho, 85

O lugar teatral e a cidade: entre o visivel e o não visivel José Simões de Almeida Junior, 95

À procura de espaço

na cena contemporânea luso-brasileira Ana Raquel Fernandes, 103

O Processo do Rei

a história no palco do cinema

Mirian Tavares, 111

\section{sala preta}

Revista de Artes Cênicas

Número 9-2009

ISSN 1519-5279

PPG Artes Cênicas

Departamento de Artes Cênicas

Escola de Comunicações e Artes

Universidade de São Paulo
Laços e desenlaces entre criação e reflexão crítica no teatro português contemporâneo Maria João Brilhante, 121

\section{MEMÓRIA E TEATRO}

A performance da memória

Beth Lopes, 135

Reflexões sobre a prática da memória

no ofício do ator de teatro

François Kahn, 147

Experimentar a memória,

ou experimentar-se na memória

Tatiana Motta Lima, 159

V. Meyerhold e a "Memória loci":

uma poética da visualização do corpo que pensa Yedda Carvalho Chaves, 171

Palavras invisiveis

José Batista Dal Farra Martins (Zebba Dal Farra), 183

A memória como recriação do vivido aplicada às artes performativas

Patricia Leonardelli, 191

\section{DOSSIE MEMÓRIA DA CANA}

Memória da Cana

Newton Moreno, 205

Da proto-performance ao espetáculo:

fronteiras nebulosas

Carlos Ataíde, 215

Ensaio de Fotos 
Bodas de Sinhá: processo de f(r)icção sob a máscara ritual de Dona Senhorinha Luciana Lyra, 221

Um olhar sobre a memória coletiva no processo teatral de Memória da Cana Mariana Soutto Mayor, 241

Um passeio pela familia patriarcal Fátima Quintas, 247

Decifra-me ou te devoro! Cassiano Sydow Quilici, 251

\section{FORMAÇÃO}

Teatro Performativo e Pedagogia Entrevista com Josette Féral, 255

Para alimentar o desejo de teatro Maria Lúcia de Souza Barros Pupo, 269

\section{DRAMA E PÓS DRAMA}

Dramaturgia: o texto e tudo mais ao redor Rubens Rewald, 281

Como fumaça sobre o lago Stephan Baumgärtel, 293

Os cadernos de Antonin Artaud André Silveira Lage, 311

\section{TEORIA}

Tradiçôes e inovações nas artes da cena Béatrice Picon-Vallin, 319
Performer

Richard Schechner, 333

O céu do teatro

Eugenio Barba, 367

Teátrica pagã:

diálogos de Jean-François Lyotard com a cena

Óscar Cornago, 371

\section{TEATRO E MÚSICA}

Três caminhos de pesquisa musical no Latão

Walter Garcia, 385

Música popular e violência urbana

em Essa Noite Mãe Coragem

Maurilio Andrade Rocha, 393

Estratégias para a criação musical

Ernani Maletta, 399

Tocando a vida

Fábio C. M. Cintra, 409

\section{LIVROS}

Escritura Politica no Texto Teatral. Ensaios sobre

Sófocles, Shakespeare, Kleist, Büchner, Jahnn,

Bataille, Brecht, Benjamin, Müller, Schleef

Maria Sílvia Betti, 419

Uma companhia moderna:

o Teatro Popular de Arte

Elizabeth R. Azevedo, 425 